\title{
Percutaneous Nephrolithotomy in an Elderly Female with Severe Kyphoscoliosis: Modified Prone Position
}

\author{
Rajendra B. Nerli, MS, MCh, PhD, MBA, ${ }^{1,2}$ Amey Pathade, MS, MCh, Shivagouda Patil, MS, MCh, ${ }^{1}$ \\ Vishal Kadeli, MS, MCh, Sreeharsha Nutalpati, MS, MCh, ${ }^{1}$ Shridhar C. Ghagane, MSc, PhD, MBA, ${ }^{3}$ \\ Neeraj S. Dixit, BSc, MBA, ${ }^{3}$ and Murigendra B. Hiremath, MSc, $\mathrm{PhD}^{4}$
}

\begin{abstract}
Percutaneous nephrolithotomy (PCNL) is one of the important options in the management of large ( $>2 \mathrm{cms})$ and complex renal calculi. Traditionally the prone position has been used to access the pelvicaliceal system as well as to remove renal calculi. Several modifications to this position have been suggested and reported by several urologists. We performed PCNL in an elderly female with a severe kyphoscoliosis by modifying the classical prone position.
\end{abstract}

Keywords: percutaneous nephrolithotomy, prone, complications, severe kyphoscoliosis

\section{Introduction}

$\mathbf{P}$ ERCUTANEOUS NEPHROLITHOTOMY (PCNL) Has become the gold standard procedure for treatment of large and complex kidney stones. ${ }^{1}$ Percutaneous access to the kidney was first used in 1954 when radiologists punctured the renal pelvis of a hydronephrotic kidney so as to perform anterograde pyelography. ${ }^{2}$ Traditionally, the prone position that was in fact developed by the radiologists has been used by the urologists to perform PCNL. Urologists have developed different modifications of the classic prone position so as to minimize the complication rates, and one among them is the supine position. We report a case of a 78-year-old female presenting to us with right sided large renal calculi. As she was a case of severe kyphoscoliosis, we had to use a modification of the classical prone position, so as to access the pelvicaliceal system, as well as remove the calculi.

\section{Case Report}

A 78-year-old female patient with severe kyphoscoliosis (Fig. 1a) presented with pain in abdomen secondary to urolithiasis. The patient was nonhypertensive and nondiabetic. Plain CT revealed a renal calculi $(\mathrm{HU}+1200)$ measuring $2.3 \times 2.4 \times 2.0 \mathrm{cms}$ in the right lower calix (Fig. 1b). Degen- erative and generalized osteopenia was noted in the entire spine with significantly reduced intervertebral spaces of the lower thoracic and lumbar vertebrae (Fig. 1c).

A PCNL was planned under general anesthesia. An initial right retrograde ureteropyelogram was done to delineate the pelvicaliceal system with the patient positioned in a lithotomy position. With proper care, the patient was put in prone position. The patient's head, thorax, and abdomen were positioned on the lower end of the operating table. The lower limbs were hanging free from the edge of the table. The knee was flexed and the legs and feet were rested on a stool covered with pillow. In this position, the $\mathrm{C}$-arm could be freely moved over the abdomen (Fig. 2a, b).

PCNL was performed using a bull's eye technique to puncture the pelvicaliceal system and track dilated using a combination of Teflon and metal dilators. The stone was fragmented using a pneumatic lithoclast. The stone was fragmented and extracted totally. The postoperative period was uneventful. The patient was discharged on the 4th postoperative day with no complications.

\section{Discussion}

Fernstrom and Johansson ${ }^{3}$ and Castaneda-Zuniga and colleagues ${ }^{4}$ performed PCNL using the classic prone position

\footnotetext{
${ }^{1}$ Department of Urology, JN Medical College, KLE Academy of Higher Education and Research (Deemed-to-be-University), Belagavi, Karnataka, India.

${ }^{2}$ KLES Kidney Foundation, KLES Dr. Prabhakar Kore Hospital and Medical Research Centre, Belagavi, Karnataka, India.

${ }^{3}$ Department of Urology, KLES Kidney Foundation, KLES Dr. Prabhakar Kore Hospital and Medical Research Centre, Belagavi, Karnataka, India.

${ }^{4}$ Department of Studies in Biotechnology and Microbiology, Karnatak University, Dharwad, Karnataka, India.

(C) Rajendra B. Nerli et al., 2019; Published by Mary Ann Liebert, Inc. This Open Access article is distributed under the terms of the Creative Commons Attribution Noncommercial License (http://creativecommons.org/licenses/by-nc/4.0/) which permits any noncommercial use, distribution, and reproduction in any medium, provided the original author(s) and the source are cited.
} 
FIG. 1. (a) Elderly severe patient with severe kyphoscoliosis. (b) $\mathrm{CT}$ shows $2.3 \times 2.3 \times 2.0$ calculi in the right kidney. (c) Degenerative and generalized osteopenia noted in the entire spine.

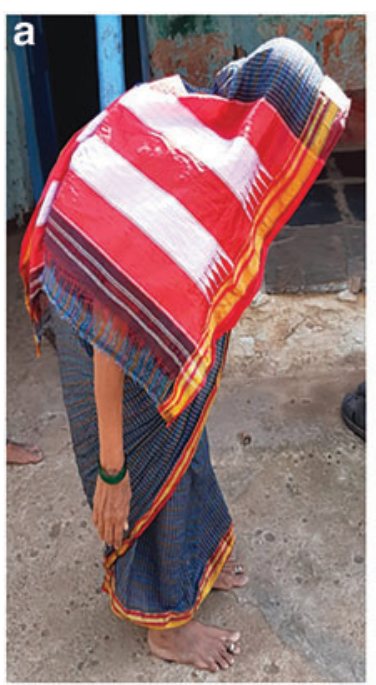

and reported excellent results with minimal complication rates. Since these early reports, PCNL has become the gold standard procedure for the treatment of large or staghorn kidney stones and all the urologists have positioned their patients in the prone position without any deviations. It took $>12$ years for the operating surgeons to start thinking and practicing various modifications of the classic prone position. Several modified prone positions were introduced, including reverse lithotomy position, prone split leg position, and prone flexed position..$^{5}$ All these prone or modified prone positions require turning the patient to the prone position with several risks including cervical spine injury and skeletal or eye complications that require extreme care in the alignment of the patient in the most neutral position.

Valdivia UrÍa and colleagues ${ }^{6}$ reported on the use of supine position as early as 1987 to position the patient for PCNL. Several genitourinary surgeons modified this position
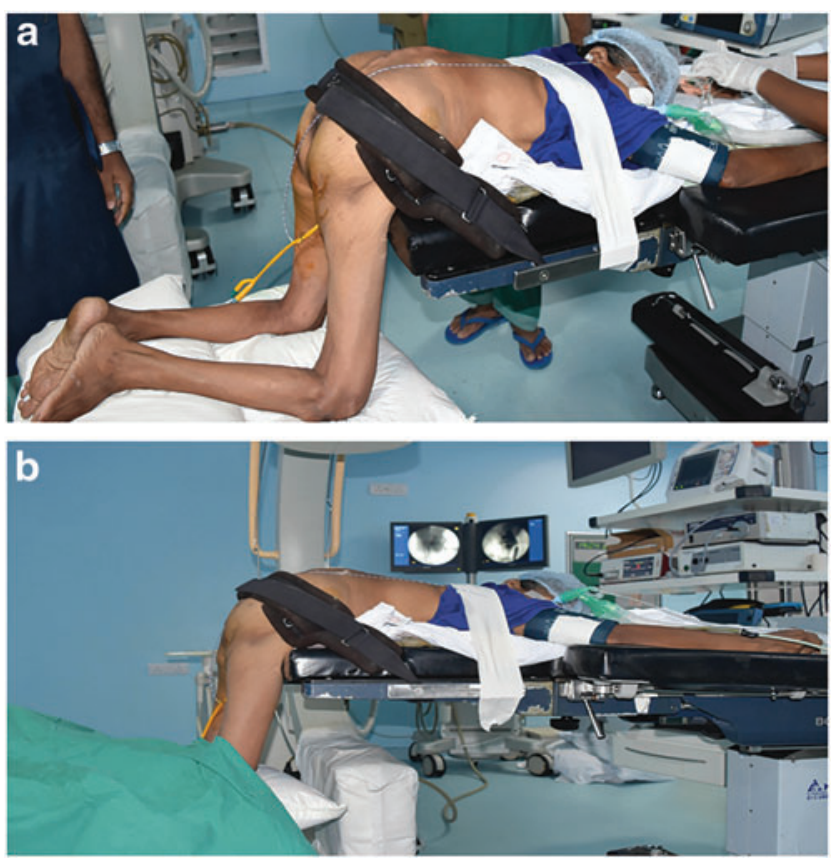

FIG. 2. (a, b) Patient positioned for percutaneous nephrolithotomy in a modified prone position.
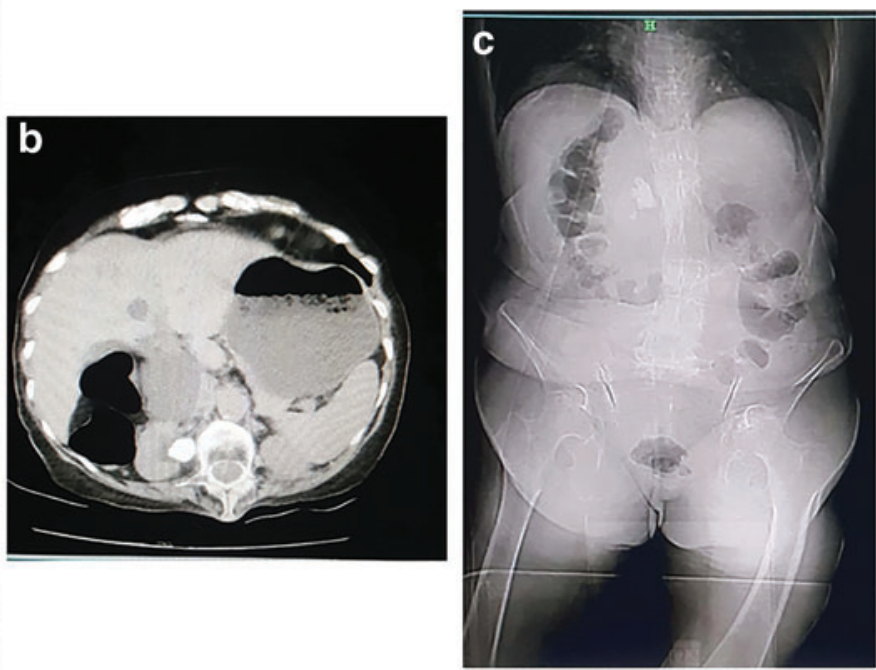

and published their results, with Galdakao-modified Valdivia position, Barts technique, complete supine position, and Barts flank-free modified position. ${ }^{5}$ The main hypothetical advantage of the supine position is the minimization of cardiac and respiratory encumbrance and the easier puncture of the upper calix. In addition, one of the most important advantages of the supine position is that it allows simultaneous retrograde intrarenal surgery. ${ }^{5}$ El-Husseiny et al. reported on the use of full lateral position for PCNL so as to minimize the hemodynamics and respiratory risks in patients with high risk. ${ }^{7}$

Our patient being an elderly lady with a severe kyphoscoliosis presented to us with the problem of positioning for any surgical procedure, including PCNL. There was a worry that during positioning, further injury to back could occur, putting the life of the patient at risk. As the patient had a small physical appearance, it was easy to position the patient in the position that has been described. Similarly patients with skeletal deformities present a challenge in the treatment of renal stones, be it for open/endoscopic surgery or even for extracorporeal shockwave lithotripsy. Moreover these patients are at an increased risk to further injuries during positioning and under general or regional anesthesia.

\section{Disclosure Statement}

No competing financial interests exist.

\section{Funding Information}

No funding was received for this article.

\section{References}

1. Nerli RB, Reddy MN, Devaraju S, Hiremath MB. Percutaneous nephrolithotomy in patients on chronic anticoagulant/antiplatelet therapy. Chonnam Med J 2012;48: 103-107.

2. Ween HS, Florence TJ. The diagnosis of hydronephrosis by percutaneous renal punctures. J Urol 1954;72;589-595.

3. Fernstrom I, Johansson B. Percutaneous pyelolithotomy. A new extraction technique. Scand J Urol Nephrol 1976;10:257-259.

4. Castaneda-Zuniga WR, Clayman R, Smith A, Rusnak B, Herrera M, Amplatz K. Nephrostolithotomy: Percutaneous techniques for urinary calculus removal. AJR Am J Roentgenol 1982;139:721-726. 
5. Nerli RB, Mungarwadi A, Ghagane SC, Dixit NS, Hiremath MB. Supine percutaneous nephrolithotomy in children. J Sci Soc 2018;45:63.

6. Valdivia UrÍa JG, Lachares SantamarÍa E, Villarroya RodrÍlguez S, et al. Percutaneous nephrolithectomy: Simplified technic (preliminary report). Arch Esp Urol 1987;40:177-180.

7. El-Husseiny T, Moraitis K, Maan Z, Papatsoris A, Saunders P, Golden B, Masood J, Buchholz NP. Percutaneous endourologic procedures in high-risk patients in the lateral decubitus position under regional anesthesia. J Endourol 2009;23:1603-1606.

Address correspondence to: Rajendra B. Nerli, MS, MCh, PhD, MBA

Department of Urology JN Medical College KLE Academy of Higher Education and Research (Deemed-to-be-University) JNMC Campus, Nehru Nagar Belagavi 590010 Karnataka India

E-mail: rbnerli@gmail.com

\begin{tabular}{|c|} 
Abbreviations Used \\
$\mathrm{CT}=$ computed tomography \\
$\mathrm{HU}=$ Hounsfield units \\
$\mathrm{PCNL}=$ percutaneous nephrolithotomy
\end{tabular}

Cite this article as: Nerli RB, Pathade A, Patil S, Kadeli V, Nutalpati S, Ghagane SC, Dixit NS, Hiremath MB (2019) Percutaneous nephrolithotomy in an elderly female with severe kyphoscoliosis: modified prone position, Journal of Endourology Case Reports 5:4, 187-189, DOI: 10.1089/cren.2019.0110. 